\title{
3rdness: Filming, Changing, Thinking Hong Kong
}

Ka-Fai Yau

\section{Thinking(,) through Cinema}

To intervene into what has been happening in the cinema, Gilles Deleuze puts forth "a taxonomy, an attempt at the classification of images and signs" to replace "a history of the cinema." His cinema project is a conceptual attempt to depart from prevailing histories of cinemas, which leave many of their own problematics unanalyzed. As he himself proclaims in his preface to the French edition of his two cinema books, "This study is not a history of the cinema." In his preface to the English edition, he reiterates: "This book does not set out to produce a history of the cinema but to isolate certain cinematographical concepts." ${ }^{2}$ Deleuze perceives that "from Plato to Bergson, we find the idea of the concept being a matter of articulation, of cutting, and cross-cutting." 3 Via his taxonomy of images and signs in his cinema books, Deleuze not only explores new possibilities in cinema. $\mathrm{He}$ also extends new possibilities of thinking(,) through cinema (new possibilities 
of thinking, through cinema; new possibilities of thinking through cinema). To him, "the task of philosophy when it creates concepts, entities, is always to extract an event from things and beings, to set up the new event from things and beings, always to give them a new event: space, time, matter, thought, the possible as events." "In this sense his cinema project is not simplistically an endeavor to construct a philosophy of cinema in place of existent histories of cinema in order to "extract an event from things and beings." It is a project aiming at actualizing "the task of philosophy" by way of the medium: cinema. Such actualization in turn entails a reconfiguration of "the task of philosophy" in light of the appearances of "new events" in this specific medium.

In Cinema $I$ and Cinema 2 Deleuze, on one hand, recategorizes issues of history, geography, and representation through his neologisms and, on the other hand, operates within conventional problematics, such as nationality, authorship, genres, canons, and stylistics. Through these problematics, accepted definitions and relationships are at the same time reconfigured and interrogated. Deleuze's cinema project sets out to explore different ways of reconceptualizing cinema, history, and thinking by means of their interactions. He regards the philosopher as a genealogist, and "genealogy means both the value of origin and the origin of values." The "value of origin" designates the constructiveness of origin as the entrance to creations and differences; the "origin of value" explicates the constructedness of value as a constant reminder against frozen hierarchies and essentialism. They are to be taken together in order to continue the dialectics among differences, facts, and representations. Lacking any of them would be a fixation that terminates the dialectics of the new. In this sense we can investigate how this "new event" heading toward differences can continue to be new in terms of cinematic practices.

Furthering this new event involves a reconceptualization of Deleuze's (re)conceptualization of cinema, which I am going to explore in relation to my discussion of Hong Kong cinema. Deleuze's project mainly concentrates on conceptualizing Euro-American cinemas, but it has also discussed nonEuro-American cinemas, such as Asian cinema, for example, including the films of Yasujiro Ozu and Akira Kurosawa, as well as the situation of filmmakers in the third world and the missing people in cinema. ${ }^{6}$ The complex 
considerations behind Deleuze's concentration on Euro-American cinemas make his (re)conceptualization even more insinuating. In the first part of this article I scrutinize certain foundational concepts in Deleuze's cinema project; in the second part I attempt to push these foundational concepts to a different terrain, a possibility of renewal. Amid this convergence on Deleuze's cinema project, we can inquire into both his (re)conceptualization and the prevalent conditions of an-o/Other terrain-Hong Kong. As an-o/Other terrain not examined in Deleuze's cinema project, Hong Kong cinema is not just the entrance to new possibilities of Deleuze's (re)conceptualization. It is also the entrance to new possibilities of thinking(,) through cinema and thinking(,) through Hong Kong.

\section{Thirdness and the Cinematic: Peirce and Bergson}

The Deleuzian cinemato-logic sets out to depart from binary linguistic systems. It operates, first and provisionally, through a ternary logic and a visual medium in line with C. S. Peirce's ternary categorization of images. To Peirce, "the first is that whose being is simply in itself, not referring to anything nor lying behind anything. The second is that which is what it is by force of something to which it is second. The third is that which is what it is owing to things between which it mediates and which it brings into relation to each other." Deleuze appropriates this triadic categorization as a logic of signs that conjoins, first, the essence; second, the o/Other; and third, the interpretation of the sign in relation to the external world, perfusing with signs. It is not the Saussurean semiology that privileges language and cultural systems. It is the "pragmaticistic semiotic," a pan-semioticism that emphasizes the transformation of signs within the communities as well as the evolving universe. Deleuze notes, "On the one hand, according to Peirce, there is nothing beyond thirdness: beyond, everything is reducible to combinations between $\mathrm{I}, 2,3$. On the other hand, thirdness, that which is three by itself, will not let itself be reduced to dualities." ${ }^{8}$ For Deleuze, it is an essay not only to depart from the binarism and humanism within Saussurean semiology but also to reframe the "universe of representations" concerning everything. His cinema project recategorizes cinematic images in order to metamorphose the mediation constituting the "universe of representations," "between an 


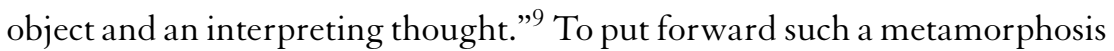
Deleuze introduces an intricate agenda by constructing a ternary system. Apart from his translated rearticulation of firstness (la priméité) (potentialities) and secondness (la secondéité) (actualities) of cinema in Cinema I and Cinema 2, there is a thirdness (la tiercéité) that lies in the middle of the preceding two. It simultaneously works as well as transforms firstness and secondness in the process of deciphering. Cinema $I$ and Cinema 2 should not be translated into Cinema one/Cinéma un and Cinema two/Cinéma deux. If one has to decipher the titles into any expressions, though they are expressive in a problematic sense, they would be Firstness of Cinema/La priméité du cinéma and Secondness of Cinema/La secondéité du cinéma. Unless the two books are translated into Arabic, the $I$ and 2 should preferably remain as symbolic numerals foreign to the linguistic contexts that are making sense of these symbols. In fact, the worldwide notation of these numerals makes them impossible to be simply Arabic. The act of reading and comprehending Cinema $I$ and Cinema 2 is where thirdness appears. One can never find the number 2 in a binary system nor the number 3 in a ternary system, and that is why a system's systematicity can never be described in its own terms. It is in this sense that Deleuze's Euro-American-based reconceptualization of cinema needs to be further reconceptualized in relation to different contexts and locations. The I and 2 form a ternary system, with a thirdness in the state of B/becoming. Deleuze's understanding of Peirce's concept of thirdness points to a "beyond" that disrupts binary reductions of things and would constantly involve another form of relation against the prevalent. "Everything is reducible to the combination of I, 2, 3," and I must note, as long as everything can be further deciphered according to the logic of a notion of thirdness. Hence, it is not the question pertaining to whether 3 is essentially better than $2 ; 1,2,3$ is not a stable combination, but a mode of disruption and change. ${ }^{10}$

Deleuze further relates this numerical logic to Henri Bergson's theses of movement and time to elucidate the transforming nexuses among images and signs. Bergson sets out to deal with the dispute between idealism and materialism regarding whether matter can be reduced to the perception of its viewing subject, or whether the object exists independently of the consciousness that perceives it. In Matter and Memory he pursues memory as an 
example that portrays the interaction between mind and body, consciousness and perception:

The truth is that memory does not consist in a regression from the present to the past, but, on the contrary, in a progress from the past to the present. It is in the past that we place ourselves at a stroke. We start from a "virtual state" which we lead onwards, step by step, through a series of different planes of consciousness, up to the goal where it is materialized in an actual perception; that is to say, up to the point where it becomes a present, active state; in fine, up to that extreme plane of our consciousness against which our body stands out. In this virtual state pure memory consists. ${ }^{11}$

To Bergson, the "series of different planes of consciousness" is constituted by the generation of frozen "planes... materialized in an actual perception." It is a depiction of how memory works on the basis of a photographic operation, a generation of frozen planes. It is already metaphorical thinking on the verge of becoming cinematic.

Such a mechanism of generation is further clarified in Creative Evolution, through Bergson's introduction of cinematography and movement into his investigation of the mechanism of knowledge:

It is true that if we had to do with photographs alone, however much we might look at them, we should never see them animated: with immobility set beside immobility, even endlessly, we could never make movement. In order that the pictures may be animated, there must be movement somewhere. The movement does indeed exist here; it is in the apparatus. It is because the film of the cinematograph unrolls, bringing in turn the different photographs of the scene to continue each other, that each actor of the scene recovers his mobility; he strings all his successive attitudes on the invisible movement of the film.... we put this [movement] into the apparatus, and we reconstitute the individuality of each particular movement by combining this nameless movement with the personal attitudes. Such is the contrivance of the cinematograph. And such is also that of our knowledge. ${ }^{12}$

Bergson's theses on movements are attempts to resolve Zeno's paradox (How can the sum of still moments be equal to movement?) by means 
of exemplifying it with new metaphors: photography and cinema. Bergson's introduction of new technology to the apparatus of knowledge launches a conception of time and space in relationship to perception and action. Perception and action are dominant in his theorization of the apparatus of knowledge. Space and time are realms mastered by this apparatus according to the following "law": "Perception is master of space in the exact measure in which action is master of time."13

Bergson's photo-cinematic portraits of the apparatus of knowledge remain controversial. However, his attempt to resolve epistemological problematics via technological media enhances new affinities between perception and space, action, and time. These new affinities are not just outcomes of Bergson's theory of knowledge that appropriates photography and cinema as new metaphors for exemplification. They are also starting points for a reconfiguration of the status of photography and cinema in modern societies, especially for a consideration of them as the apparatuses of knowledge in the age of technology, as well as the age in which Western technology and media penetrate different locations and cultures. Although Bergson ultimately denigrated cinema, Deleuze retrieves the Bergsonian perception of cinema to develop a new exegesis for rethinking cinema.

\section{The Geohistorical: The Three Time-Images}

Regarding modern cinema, Deleuze's thesis is this: Since the spatial changes after World War II, time dominates in modern cinema. He elaborates by defining neorealism and the new wave at the beginning of Cinema $2 .{ }^{14} \mathrm{Via}$ his definition of neorealism and the new wave, space, time, and representation are explored in relation to geography, history, realism, aesthetics, and politics vis-à-vis certain external dynamics.

"Why Italy first, before France and Germany?” Deleuze asks.

It is perhaps for an essential reason, but one which is external to the cinema. Under the impetus of de Gaulle, France had, at the end of the war, the historical and political ambition to belong fully to the circle of victors ... [and] to appear as a contribution to victory. These conditions were not favourable to a renewal of the cinematographic image, which 
found itself kept within the framework of a traditional action-image, at the service of a properly French "dream". The result of this was that the cinema in France was only able to break with its tradition rather belatedly and by a reflexive or intellectual detour which was that of the New Wave. The situation in Italy was completely different. It could certainly not claim the rank of victor; but, in contrast to Germany, on the one hand it had at its disposal a cinematographic institution which had escaped fascism relatively successively, on the other hand it could point to a resistance and a popular life underlying oppression, although one without illusion. To grasp these, all that was necessary was a new type of tale (récit) capable of including the elliptical and the unorganised, as if the cinema had to begin again from zero, questioning afresh all the accepted facts of the American tradition.... it is this very special situation of Italy which made possible the enterprise of neo-realism. ${ }^{15}$

In Cinema 2 Deleuze utilizes various European cinemas, such as neorealism, new wave, and new German cinema, to identify moments and locations becoming modern through a scrutiny of the time-image and its variances in different geohistorical situations. Also in response to its specific geohistorical situations, an o/Other cinema of thirdness begins, when the new Hong Kong cinema has been responding to new geohistorical situations via new cinematic images. It should not be confused with a "third cinema" under the obsolete Three Worlds Theory, while it indeed is an attempt to canvass the way cinema responds to geohistorical situations in a non-Euro-American location.

Ackbar Abbas considers the signing of the Sino-British Joint Declaration in 1984 , which set the parameters of Hong Kong's returning to China, and the events of Tiananmen in I 989 as the catalysts that provoked the anxieties over 1997. ${ }^{16}$ The distance between Hong Kong and China after a century of changes can in no way be easily proselytized through a declaration and a basic law. "Now faced with the uncomfortable possibility of an alien identity about to be imposed on it from China, Hong Kong is experiencing a kind of last-minute collective search for a more definite identity." 17 This creates the dynamics by which what Abbas calls a new Hong Kong cinema visualizes the flux and discrepancy within the subjectivity of Hong Kong culture. 
It specifies the multifarious and contesting features, market relations, and politics within the complex and suggestive processes of the formation of a Hong Kong subject in cinema.

Not that all Hong Kong films in this period are examples of this "new" cinema, nor is it a cinema consequential to the 1997 effect and at the same time fertile for the creation of a Hong Kong identity. Such a cause-andeffect method of explaining cultural changes through political changes is what Kwai-cheung Lo calls a "mechanical determinism." He perceives that it is a historical approach that takes specific events and times as the origin of a Hong Kong identity. ${ }^{18}$ Lo criticizes Matthew Turner's perception that the ig6os were a break, especially after the political riots in $1966-1967$, that marks the construction of Hong Kong's modern identity in place of "an ambivalent identity, many displaced huaqiao communities and overseas Chinese." ${ }^{19}$ Lo finds "Turner's perception of the relationship between history, identity, and the body ... based on a simple model of causality.... Such an approach of mechanical determinism fails to acknowledge that the surface phenomenon itself could be more than the appearance of an underlying content." The "clear historical cut in this [Turner's] analysis trims off the radical heterogeneity of the effect by tying it up neatly with the cause." ${ }^{20}$ On the other hand, Lo also rejects the antihistorical understanding of Hong Kong movies as "simply, some of the most entertaining films on the planet." 21 This also touches on the problems concerning whether popular cinema is more representative than art cinema, if the distinction between these two cinemas, though problematical and ambiguous, still exists and therefore cannot be simplistically ignored. The point is not whether the films of Wong Kar-wai, Ann Hui, and Fruit Chan can represent a valid Hong Kong, while John Woo and Wong Jing cannot. Certainly there are films that definitely explore questions of Hong Kong identity while not being very popular in terms of box office receipts; there are also very popular films that can hardly be called investigations of the subjectivity of Hong Kong culture. With few exceptions, the "Hong Kong cinema has to be popular in order to be at all." The point is that "there are different ways of being part of the mainstream." 22 Abandoning the obsolete commercial-alternative opposition, our entrance points, among others, are the geohistorical situations that dominate the Hong Kong political arena and the general public's concern. However, in the films I am 
going to discuss, these entrance points appear only covertly and indirectly in a minor way, in the sense that they are concerned with potentialities, actualities, and interpretations dwelling on the major as a problematic. This minor cinema certainly cannot represent the whole of Hong Kong cinema. But it also highlights the potentialities, actualities, and interpretations of Hong Kong cinema that cannot be covered by dominant discourses on Hong Kong and its cinema. ${ }^{23}$

The new Hong Kong cinema is a concept that dwells on the various responses to geohistorical situations from the early I 980 os to around I997, when the return of Hong Kong to China became (one of) the issue(s) of greatest concern in Hong Kong. This concept articulates the responses in Hong Kong films relevant to such an agenda, instead of interpreting all Hong Kong films in this period in terms of this agenda. It is a term that is in effect neither historical nor formal. I grasp it as a strategy that appropriates cinematic images to rechannel and rethink the politics and aesthetics of Hong Kong and certain issues in its cinema. It is not a generalization of what Hong Kong and its cinema in this period are, not only because they are too diverse to be pinned down by a few grand statements, but also because it is an overtly selective articulation of trends and potentialities in the cinema of Hong Kong. It surely cannot claim to represent the general panorama of Hong Kong cinema, but it conceptualizes a thread of Hong Kong films responsive to the political conditions of Hong Kong. Such a conceptualization itself is also a political response to other existing understandings and conceptions of Hong Kong cinema in terms of, for example, market relations, nationalism, cultural influences, social mobility, and sexual identities. The conception of a new Hong Kong cinema itself is an endeavor to initiate thirdness out of prevailing representations of both Hong Kong cinema and other Western cinemas. If Abbas's "about 1982, Hong Kong" can really be seen as a beginning, ${ }^{24}$ it is just a beginning postulated in reaction to Deleuze's "around I948, Italy; about I958, France; about I968, Germany" in order to pinpoint the dynamics of the responses of specific cinemas to different geohistorical situations. ${ }^{25} \mathrm{It}$ is in addition to this reaction that I set out to continue reconceptualizing a "minor Hong Kong cinema" in connection with Hong Kong's geohistorical situations. 


\section{Toward a Minor Hong Kong Cinema}

In this article I am not going to survey the Hong Kong cinema between I982 and I997, an impossible task for just one article. In this section I only consider Deleuze's third time-image in relation to the responses of certain Hong Kong films to new geohistorical situations. This does not mean that these Hong Kong films can be easily categorized as series of time-images that Deleuze identifies with modern cinema in contrast to the movementimages in classical Hollywood cinema. From a formalist perspective, many of these films indeed share some of the features of the movement-images Deleuze outlines in his examination of classical Hollywood cinema. If we analyze what he regards as modern cinema and time-images employing his examples in detail, such as Italian neorealism, the French new wave, and the new German cinema, we would find them, on one hand, too multifarious to be generalized and, on the other hand, continuing certain features of the movement-images. In Cinema I, he concentrates on "the dispersive situation, the deliberately weak links, the voyage form, the consciousness of cliches, the condemnation of the plot" to lay out what he regards as "the new image," the time-image. ${ }^{26}$ Although one cannot avoid identifying them in certain formalist ways, they are in effect not just formal features, since they have different meanings in different cultural contexts. My attempt to relate them to the context of Hong Kong cinema is itself an effort to reveal such differences. My discussion of Hong Kong cinema highlights certain complexities and connotations that are themselves interventions toward reconceptualizing cinema, Hong Kong, and Hong Kong cinema as well as certain existing modes of conception. Deleuze's appropriation of Peirce's concept of thirdness is an endeavor that aims at a "beyond" that disrupts binary reductions of things. This endeavor sets out to enter the state of $\mathrm{B} / \mathrm{becoming}$-reading and deciphering. Thus Deleuze's thesis itself implies its constant reconfiguration in connection with different geohistorical situations.

In the chapter "Peaks of Present and Sheets of Past: Fourth Commentary on Bergson," Deleuze mentions "two possible time-images, one grounded in the past, the other in the present." 27 The former can be found in Citizen Kane in the recollection of Kane's life through the perspectives and narratives of various persons. The film centers on the mystery of Kane's character. As a 
very wealthy and influential figure in the United States, he was loved and hated by millions of Americans. Kane as an object of recollection is dead from the very beginning. In the film "Rosebud" triggers "circles or sheets of virtual past," slices of Kane's life. Via different people's recollections of Kane's life, each of these circles or sheets contains "the Whole of Kane's life in one form or another." 28 These different versions and periods of Kane's life correspond to the actual present, a point that triggers multiplicity. The latter time-image can be found in the encounter in Last Year in Marienbad (I96I) in which the "peaks of present" are "constantly revived, contradicted, obliterated, substituted, re-created, fork and return ... in a kind of Augustinianism." 29 In the film, characters in the present interact with one another along the fluxes between memories and amnesia in which proof of events in the past is determined by temporal orders. Their relationships "essentially concerned the order of time, that is, the coexistence of relations or the simultaneity of the elements internal to time." ${ }^{30}$ While the first time-image begins with a present that arouses sheets of virtual past, the second time-image commences with the fleeting past that valorizes multiple presents.

In contrast to the previous two time-images illustrated in one whole chapter of Cinema 2, there is a third time-image that occupies just one paragraph with two examples from Jean-Luc Godard. The first example (Masculin féminin) states a "method of the image" that requires further development: "In Masculin féminin, the fictional interview with the characters and the real interview with the actors mix together so that they seem to be speaking to each other, and to speak for themselves, by speaking to the film-maker. The method can be developed only where the camera is constantly reaching a before or an after in the characters which constitute the real, at the very point where story-telling is set in motion." 31 The second example (France tour détour deux enfants) is illustrated only through one bit of quoted dialogue: "Him before, and the story after, or him after and the story before." 32 It is said to have made use of this third time-image as a principle. In this principle, "story-telling is set in motion," that is to say, bringing the before and the after, the cinema of fiction and the cinema of reality, together.

In the next section I discuss to what extent the three time-images can be found in Hong Kong cinema, especially the third, which requires further development and reformulation in connection with different examples 
from different geohistorical situations. This is not an attempt to transplant cinematic concepts from one domain to another, or should I say it involves a transplantation that puts its own connotations on-screen. It is via such transnational screening that modern cinema presents intercultural dynamics and politics amid displacement and deplacement in response to geohistorical situations.

\section{The Three Time-Images in Hong Kong}

In the new Hong Kong cinema various aspects of all three time-images are extensively revealed and reviewed. In Center Stage [Ruan Lingyu], "the method" articulated in Godard's Masculin féminin is developed further: Two famous actresses, one from China in the I93os and one from Hong Kong in the I980s and I990s, respond to each other by their appearances in film excerpts. Notwithstanding that they are from two different eras, they present and discuss their careers, loves, families, friendships, and fame via juxtaposing film excerpts.

Compared to Deleuze's perception of "the deliberately weak link" as a feature of the new image, Center Stage establishes overt links by way of disruptions and caesuras that conversely manifest the weakness of the link. Apart from the two actresses, even Stanley Kwan, the present filmmaker; the filmmakers of the old excerpts; and contemporary audiences are all juxtaposed into these temporo-virtual dialogues. The juxtaposition of Maggie Cheung, the present famous actress, reenacting Ruan Lingyu, the famous actress of the I93os, as well as Cheung's dialogues with the director in between her own acting, blurs the distinctions between story and history, fiction and reality, acting and living. Film is a medium that is inevitably manipulated and a narrative that is inescapably fictional. In this medium the filmic appearances of the two famous actresses are unavoidably viewed as acting, though acting can still embody its own truths in its own performance (another example regarding Maggie Cheung is her acting as Maggie Cheung herself in Irma Vep [1996] ). Nonetheless, there are two private lives of two real figures/actresses, who are undeniably actual (though they are actresses). In addition to the contrast of their careers, there are also rumors about both Ruan and Cheung concerning their deception and betrayal by their lovers. In Center Stage there 
are caesuras that cut across sequences of narratives to create a site of the indiscernible - there are the real in the fictional and the fictional in the real in a series of juxtapositions. It is a virtualization bridging the spatiotemporal gap between the two actresses in a narrative by which disparate series of old and new images can narrate along caesuras. These caesuras punctuate and initiate interactive responses among images from different spaces and times. The series of time-images in this film trigger intertextual dialogues and responses, through which spatiotemporal orientations of images are opened to contests from different spaces and times. Through these responses and dialogues the film gives rise to "a before or an after in the characters which constitute the real at the very point where story-telling is set in motion." 33

With reference to the befores and the afters, the series of recollectionimages in the beginning of Ann Hui's Song of the Exile [Ketu qiuhen] cut back and forth between the memories of Hue Yan and her mother. The film can also show what Deleuze's second example (France tour détour deux enfants) exemplifies. It brings the before and the after together in order to set storytelling in motion. These series of recollection-images of Hue Yan and her mother provoke reinterpretations of each other. By way of narrating the growth of Hue Yan and her familial background, the tensions in the relationships among her mother, father, and grandparents are presented in connection with historical and cultural prejudices, misunderstandings, differences, and events.

In the film both the personal and the political histories are actualized by disjunctive series of recollection-images that disagree with each other. Hue Yan's memory about her harsh mother and her kind grandparents contrasts with the memory of Hue Yan's mother about her harsh in-laws and her difficult situation as a Japanese woman in a Chinese family just after World War II. In this contrast the actual past is virtualized within the circuit of interfalsifying. The disharmonious relationship between Hue Yan and her mother can be understood in line with Hue Yan's impression of her harsh mother in Hue Yan's childhood memory. But her mother's arduous situation owing to cultural differences and prejudices reframes the audience's understanding and even produces sympathy for her harshness. Neither Hue Yan nor her mother is a liar in these series of recollectionimages. On the contrary, it is the gap between their recollections, that is to 
say, the site of interfalsification, which generates the multiplicity of "truth" within the film's narrative. "The recollection-image is an image which is actualised or in process of being made actual, which does not form with the actual, present image a circuit of indiscernibility." 34 This is the state of narration that "ceases to be truthful, that is, to claim to be true." 35 These pasts and presents are neither contradictory presents nor fake pasts. In Song of the Exile multiple pasts and presents in various locations flow along the timeimages that transfer them from one to the other in terms of both locations and eras.

"The dispersive situation" and "the voyage form" of the film enhance courses of rethinking among different presentations of events and their figures. The pasts entail more than one present, and the presents require more than one past. At the end of the film Hue Yan, her mother, and her grandparents are all put intoforeign locations that challenge their senses of belonging based on patriotism, familial relationships, and childhood memories. Hue Yan does not belong to her happy childhood in Macau, where her father is often not at home and she is sometimes happy when she is with her grandparents and sometimes unhappy when she is with her harsh mother. She also does not belong to her education in England, where she is frustrated in her application for a post in the BBC. She even has a very bad impression of Hong Kong with regard to "the worst lives and language" demonstrated by her mother, let alone Guangzhou and Japan where she is just a visitor. Even when she begins to plunge into her career as a journalist in Hong Kong, she feels compelled to visit her grandparents trapped in Guangzhou during the Cultural Revolution. The film ends with a scene in which Hue Yan's identity problem remains unsolved. Hue Yan's mother, too, fails to belong anywhere comfortably. She does not feel a sense of belonging to northeast China, where she married, nor to her harsh life in Macau. She does not belong to Hong Kong, either, the place she wants to leave when she is frustrated by her relationship with her doughter. And though she is from Japan, it is just a place she wants to return to after she argues with and wants to exasperate her daughter. The sense of belonging that Hue Yan's grandparents created for themselves is also problematic. They insist that they firmly belong to their "mother country," China. This is the case even after their torturous life in the People's Republic of China (PRC), which contrasts 
remarkably to their comfortable life in Macau, a place they consider foreign. Their torturous life and disappointment (though Hue Yan's grandfather still aspires toward China's future) in the PRC in fact signify the distance between the mother country in their mind and the mother country in their lives. China therefore, is not "Chinese" in terms of their insistences on traditional values and concepts, which are all major objects of attack during the Cultural Revolution. Through dispersive situations and voyages the film challenges imaginary orientations between people(s), places, cultures, nationalities, and historical events.

In Song of the Exile, England, China, Hong Kong, Macau, and Japan constitute a chain in which characters and places are dislocated. The timeimage is never in either the present or the past tense. It is an inter-action or even an inter-pluralization of provisional pasts, presents, and futures in undetermined spaces. It is an any-space-whatever (espace quelconque), "a space of virtual conjunction, grasped as pure locus of the possible. What in fact manifests the instability, the heterogeneity, the absence of link of such a space, is a richness in potentials or singularities which are, as it were, prior conditions of all actualisation, all determination." 36 In this space the possible is activated in order to depart from the domination of the actual. As in Song of the Exile, the singularities of the personal imaginaries are activated in order to depart from the real. It is interesting that the opposite of the true is not the false in its literal sense here. Instead, between disjunctive and competing actualities and imaginaries something else is discerned. This is what Deleuze calls "the power of the false" that points to the possible other as an entrance of intervening into the true, and vice versa. The actual is in turn set in motion to challenge the constructedness and painful arbitrariness of the imaginary. In the two aforementioned films the third Deleuzian time-image is exemplified in different geohistorical situations that in turn reconfigure the definition of this third time-image. And it is in this process of encountering new situations that we can find thirdness in this third time-image. "The power of the false" does not negate reality; it extends reality beyond transplanted thresholds of comprehension, as the new Hong Kong cinema struggles to face the transfer of its own sovereignty from one state to another.

Stanley Kwan's Rouge uses the extremes of the true and the false in its presentation of Hong Kong with this "power of the false." The film is structured 
by a series of what Deleuze calls recollection-images or mnemosigns, a series of virtual images that enter "into a relationship with the actual image and extends it." ${ }^{37}$ Fleur (Ruhua) is a courtesan who searches for her lover Chen Zhenbang. They committed suicide in 1934 because of the disavowal of their relationship by Chen's wealthy merchant family. Chen fails to appear in the realm of the dead after their suicides so that Fleur has to return as a ghost to modern-day I 987 Hong Kong to find Chen. Fleur's recollection of her previous life draws interesting comparisons to the recollections of Kane's multiple pasts in Citizen Kane to get the frozen past going beyond any single "real" version. Rouge's revision of the history and customs of brothels in the I930s Hong Kong red-light district Shek Tong Tsui derives from a female specter's flashback concerning her own love story. It is a virtual revision from a spectral recollection, a vision that is by definition not natural but supernatural, and thus beyond affirmation and denial. It is this spectral recollection that both presents tempting objects of realism-history and customs - and puts them in question: "The question of the flashback is this: it has to be justified from elsewhere, just as recollection-images must be given the internal mark of the past from elsewhere. The circumstances must be such that the story cannot be told in the present. It is therefore necessary for something else to justify or impose the flashback, and to mark or authenticate the recollectionimage." ${ }^{38}$ In Rouge such flashbacks are justified, marked, and authenticated by turning this spectral vision into a cliché and "what has never been" at the same time. A cliché is that which is so real to the extent that even mentioning it is superficial, let alone proving it; "what has never been" is that which is totally invented, unprecedented. If histories and customs can be the mark of the past, they must be clichés so that almost everyone takes them for granted and uses them to justify a past. Within the recollection-images, clichés are regarded as the marks of the past to be referred to in order to justify present recollections of the past. Nevertheless, Rouge's consciousness of clichés is itself a twist. Fleur's memory and narration revitalize customs and histories that cannot be found in most Hong Kong history textbooks. People may attempt to prove their realness through old newspaper advertisements and stories told according to old people's memories, as in the search of Fleur's human friends, Yuen Yongding and Ling Chujuan, for Chen. But all these 
customs and histories derive only from a ghost's memory within a story narrated along cinematic flashbacks. The fictionalization of such "mark [s] of the past" in cinema metamorphoses them into "what-have-never-been." Instead of presenting the unmediated true, Rouge visualizes the extremely true and the extremely false. Deleuze appropriates Bergson's thesis on perception to define cliché as the perception of "only what we are interested in perceiving, or rather what it is in our interest to perceive, by virtue of our economic interests, ideological beliefs and psychological demands. We therefore normally perceive only cliché." 39 It is not surprising that in Rouge the spectral vision has to be humanized into cliché, as it always is, in order to be present. Hence the spectral vision cannot be the unreal so long as it exists as a series of images fashioned by cliché, in other words, that which is recognized as so real that mentioning it becomes redundant. It is a repressed human vision that needs to be virtualized for the sake of getting beyond the real, the true, or the actual. Making things visible does not make things more graspable; rather, customs and histories are virtualized in a supernatural vision in a contrived medium-cinema. In Rouge cliché is combined with what-has-never-been by the recollection-images or mnemosigns that actualize supernatural narratives, on one hand, and virtualize histories and customs, on the other. Vis-à-vis Fleur's love story, Yuen's and Ling's modern love story is so hollow and ordinary, having little to be narrated. The present is exactly that which is mute. This allows us to see how the present is reworked here, as in Last Year in Marienbad's undeterminable presents as consequences of the fluxes of memories and amnesias pertaining to the pasts. In Rouge, while dis-placing a "story that cannot be told at present" into a spectral flashback, histories and customs rely on sequences of a ghost's memories to justify themselves. Nevertheless these sequences of supernatural memories turn out to be more falsifying than justifying. Fleur, a dis-placed figure (a ghost), interacts with the disjunctive space-time (the human world she returns to after fifty years in limbo, where things have been changing so fast that her memory and the present location can no longer fit into each other). This points toward the movements of time in the time-images that falsify coexistent sequences of pasts and presents. 
From Rouge's spectral recollection to Song of the Exile's falsifying memories to Center Stage's caesuras of the indiscernible, the actual and the possible tell stories that "cannot be told" in the light of the feeling of déjà disparu:

What is new and unique about the situation is always already gone, and we are left holding a handful of clichés, or a cluster of memories of what has never been. It is as if the speed of current events is producing a radical desynchronization: the generation of more and more images to the point of visual saturation going together with a general regression of viewing, an inability to read what is given to view-in other words, the state of reverse hallucination. ... If hallucination means seeing ghosts and apparitions, that is, something that is not there, reverse hallucination means not seeing what is there. ${ }^{40}$

Such a "radical desynchronization" regresses viewing experience to viewing disappearance. One cannot see what is there, but only the coexistence of the extremes of what is supposed to be there. Nonetheless, this conversely transforms our supposition about what is there, and we have no way to go back to the point where we commence our lost supposition.

Wong's Ashes of Time [Dongxie xidu] (1994) expresses this radical desynchronization of viewing experience by way of visualizing the indiscernible. The film adapts Jin Yong's substantially influential martial art novel The Story of the Vulture Shooting Hero [Shediao yingxiong chuan]. ${ }^{41}$ In the film martial arts and the Chinese Hong Kong identity intervene into each other by means of blurred images. However, the former does not signify the latter. Rather, the film employs an awry representation of the martial arts to denote the elusive and changing identity that can only be uneasily Chinese Hong Kong. If Bruce Lee's "Chinese Kung Fu" and Jacky Chan's and Sammo Hung's swift antics can be considered Hong Kong/Chinese/Asian owing to the use of martial arts in their films as the symbol of nationalism and identity, Ashes of Time shelters such symbols from view. Energetic punches and kicks can in no way be seen in Wong's cinema as in the films of Bruce Lee, Jacky Chan, and Sammo Hung. "Things have now been speeded up to such an extent that what we find is only a composition of light and color in which all action has dissolved." 42 Actions are so fast that the audience cannot even see who is beating and slashing whom. If Jin Yong's martial arts 
novel can still signify a form of nationalism in Hong Kong as well as other contemporary Chinese societies, Ashes of Time's unrecognizable adaptation of The Story of the Vulture Shooting Hero and the film's un-Chinese costumes make Jin Yong and the martial arts become what they are not. Jin Yong is there only in the film title, the characters' names, and some very minor plots that remind the audience how the main plot of the novel is overhauled. In the film any nationalism and identities that can be claimed under the Hong Kong/Chinese/Asian labels are turned into blurred images, fragmented actions, condemned plots, and dispersive situations. The intermingling love relationships among the characters move them from one place to another, and at last even Ouyang Feng leaves his own place.

The film places the first and the second time-images in reaction to each other. In Ashes of Time the peaks of present and sheets of past are knitted into one another as a net that indicates movements of time in terms of genres, space, time, narrative, heroism, characterization, camera movements, character relationships, and so on. ${ }^{43}$ Ouyang Feng, Huang Yao Shi, and Maggie Cheung wait in the present because of their past. The Blind Swordman, Hong Qi, and the girl who requests someone to avenge her brother are all figures initiating actions in the present. Ouyang Feng counts the book of fortune and the almanac day by day to access the future. In the later part of the film the subtitles mention Hong Qi's and Ouyang Feng's deaths in the future, through which the present is reinterpreted via the future. Through the intermingling and inter-intriguing of waiting and memories in the light of the past, urges of actions in the present, and deaths and destinies in the future, series of time enter movements that bring together the before and the after into a becoming. Instead of pinning down these moving moments, the time-images in the film introduce an enduring interval in the moment itself. ${ }^{44}$ The viewing experience becomes an experience of time in motion.

\section{A Transnational Projection On-screen}

There is a contrast among Deleuze's three types of time-image: between the elaborate illustration of the first and the second time-images in Citizen Kane and Last Year in Marienbad (as well as some of Alain Resnais's and Alain Robbe-Grillet's works) and the simplicity of the third time-image there is 
a transnational projection of aspiration on-screen. In his study of Cinema $I$ and Cinema 2, D. N. Rodowick observes, "Of the three chronosigns, the construction of time as series (sometimes called the genesign) is ... the least clearly defined in the cinema books, throughout which are scattered discussions of series. The difficulty of the concept also does not lend itself well to a formal description through close analysis." ${ }^{25}$ Rodowick's observation unequivocally corresponds to his discussion of Deleuze's concept of "minor literature" in which Franz Kafka's writing is perceived as a minor literary practice subverting established and frozen hierarchies. This informs Rodowick's concept of minor cinema based on Deleuze's new taxonomy of images and signs. In view of these "least clearly defined" chronosigns, Rodowick pinpoints minor cinema this way: "Rather than being based on a unified or unifying discourse, minor cinema must produce collective utterances (énoncés collectifs) whose paradoxical property is to address a people who do not yet exist and, in so doing, urge them toward becoming." 46 The new Hong Kong cinema exemplifies all three time-images by means of its intermingling features (in terms of genres, space, time, narrative, characterization, camera movements, character relationships, and so on) and geohistorical situations relating to a politics and aesthetics of de-placement. That which Deleuze identifies as the five apparent characteristics of the new image, "the dispersive situation, the deliberately weak links, the voyage form, the consciousness of clichés, the condemnation of the plot, ${ }^{\prime 47}$ point to the thirdness he longs for. Through this thirdness, so importantly, the three time-images can connect and interpenetrate and try to break away from duality. Not that the new Hong Kong cinema is so unique (although it has its own singularity, specific features, and contexts) that it exemplifies the three time-images, especially the third one. But the third time-image is a not-yet-domesticated possibility, to which Deleuze's cinemato-logical thinking aspires. Hence elaborate examples within the interpretive mode of such thinking should be (not are) always not-there. Until it is de-placed (to speak like Deleuze, deterritorialized), these movements among order of time and series of time can really be readily elaborated by fusions of the Euro-American contexts and another/Other space-time(s). This article can only initiate a starting point for reconceptualizing Hong Kong cinema as a minor cinema of differences. Developing this starting point requires a more detailed survey of the period of 
Hong Kong cinema I have examined. This strategy of reconceptualization can also be extended to other periods and examples of Hong Kong cinema, not as a description but as a point of intervention.

\section{Notes}

I Gilles Deleuze, "Preface to the French Edition," in Cinema I: The Movement-Image, trans. Hugh Tomlinson and Barbara Habberjam (Minneapolis: University of Minnesota Press, I996), xiv.

2 Deleuze, Cinema I, ix.

3 Gilles Deleuze and Félix Guattari, What Is Philosophy?, trans. Graham Burchell and Hugh Tomlinson (London: Verso, I994), I6.

4 Ibid., 33 .

5 Gilles Deleuze, Nietzsche and Philosophy, trans. Hugh Tomlinson (London: Athlone Press, 1983), 2.

6 See Gilles Deleuze, Cinema 2: The Time-Image, trans. Hugh Tomlinson and Robert Galeta (Minneapolis: University of Minnesota Press, I989), 215-224. For my discussion of Deleuze's idea of the missing people in his cinema books see Ka-Fai Yau, "Recon-figuration: Revisiting Modernity and Reality in Deleuze's Taxonomy of Cinema," Wide Angle, October 1998, 5 I-74.

7 Charles Sanders Peirce, The Collected Papers of Charles Sanders Peirce, ed. Charles Hartshorne and Paul Weiss (Cambridge, Mass.: Harvard University Press, I93 I-I935), vol. I, paragraph 356.

8 Deleuze, Cinema I, I97.

9 Peirce, Collected Papers, paragraph 480.

Io Deleuze asks, "Why does Peirce think that everything ends with thirdness and the relationimage and that there is nothing beyond?" Deleuze considers that Peirce's thirdness is "a limit of the system of images and signs" (Cinema 2,33) because from the point of view of the movement-image, "a logic of relations seems to close the transformation of the movementimage by determining the corresponding changes of the whole." Hitchcock's cinema brings forth this logic to perfect the classical cinema. Nevertheless, Deleuze also considers that there is a time-image, the opsign (or sonsign) in modern cinema, that "sets everything off again, from the inside" (ibid., 34). In this sense, to him thirdness is not simplistically about I, 2, and 3 , relating to a specific numeric system of image and signs. It is, rather, a mode of disruption that mutates the prevalent.

I I Henri Bergson, Matter and Memory, trans. Nancy Margaret Paul and W. Scott Palmer (London: Allen and Unwin, I919), 319; original emphasis.

I2 Henri Bergson, Creative Evolution, trans. Arthur Mitchell (London: Macmillan, I920), 322.

I3 Bergson, Matter and Memory, 23; original emphasis. 
I4 Deleuze, Cinema 2, I-I3.

I5 Bergson, Matter and Memory, 2 I I.

I6 Ackbar Abbas, Hong Kong: Culture and the Politics of Disappearance (Hong Kong: Hong Kong University Press, I997), 6.

I7 Ibid., 4 .

I 8 Kwai-cheung Lo, "Muscles and Subjectivity: A Short History of the Masculine Body in Hong Kong Popular Culture," Camera Obscura, no. 39 (September I996): I04-I 25.

I9 Matthew Turner, “6os/9os: Dissolving the People," West Coast Line, no. 2 I (winter I996-I997): 90.

20 Lo, "Muscles and Subjectivity," ıо8.

2 I Stefan Hammond and Mike Wilkins, eds., Sex and Zen and $a$ Bullet in the Head: The Essential Guide to Hong Kong's Mind-Bending Films (New York: Fireside, I996).

22 Abbas, Hong Kong, 21, 20.

23 Ka-Fai Yau, “Cinema 3: Towards a 'Minor Hong Kong Cinema," Cultural Studies I5, no. 3 (200 I): 353-373.

24 Abbas adds the birth of a new Hong Kong cinema to Deleuze's suggestion about when various European cinemas became "modern”: “According to Gilles Deleuze, the various European cinemas became 'modern' at different times, but always at the moment when they had to come up with new cinematic images in response to new historical situations: 'The timing is something like: around i948, Italy; about 1958, France; about i968, Germany.' We might now arguably add, going beyond Europe, about i982, Hong Kong, which was the year of Margaret Thatcher's visit to China. Since that date, it has become increasingly apparent that a new Hong Kong cinema has been emerging” (ibid., I6).

25 Deleuze, Cinema I, 2 I I.

26 Ibid., 2 Io; original emphasis.

27 Deleuze, Cinema 2, 98-i 25, quote on 98.

28 Ibid., ro6.

29 "X lives in a present of past, A lives in a present of future, so that the difference exudes or assumes a present of present (the third, the husband)" (ibid., Ior).

30 Ibid., I 55 .

3 I Ibid., I54.

32 Ibid.

33 Ibid.

34 Ibid., 54 .

35 "This is not at all a case of 'each has its own truth', a variability of content. It is a power of the false which replaces and supersedes the form of the true, because it poses the simultaneity of incompossible presents, or the coexistence of non-necessarily true pasts" (ibid., I3I).

36 Deleuze, Cinema I, ıo9.

37 Deleuze, Cinema 2, 335. 
38 Ibid., 48 .

39 Ibid., 20.

40 Ibid., $26,6$.

4I The novel was serialized in the Hong Kong newspaper Xianggangshangbao and has been adapted into numerous TV series, comics, films, etc.

42 Abbas, Hong Kong, 32.

43 For a detailed analysis of Ashes of Time's subversion of genre, concepts of time and space, heroism, characterization, camera movements, character relationships, and so on, see ibid., i6-62.

44 Deleuze, Cinema 2, 275.

45 D. N. Rodowick, Gilles Deleuze's Time Machine (Durham, N. C.: Duke University Press, I997), I4I.

46 Ibid., I54.

47 Deleuze, Cinema I, 2 Io; original emphasis. 
Copyright $\odot 2002$ EBSCO Publishing 